\title{
Prevalence of hookworm infection: A retrospective study in Kumasi, Ghana
}

\author{
Williams Walana ${ }^{1,}$, Eric Nana Kofi Aidoo ${ }^{2}$, Ezekiel Kofi Vicar ${ }^{1}$, Samuel Crowther Kofi Tay ${ }^{2}$ \\ ${ }^{1}$ Department of Clinical Laboratory Sciences, School of Medicine and Health Sciences, University for Development Studies (UDS), \\ Tamale, Ghana \\ ${ }^{2}$ Department of Clinical Microbiology, School of Medical Sciences, Kwame Nkrumah University of Science and Technology (KNUST), \\ Kumasi, Ghana
}

\section{Email address:}

walanawilliams@yahoo.com (W. Walana), lerylex@yahoo.com (E. N. K. Aidoo), kvicar@yahoo.com (E. K. Vicar), scktaysammy9@yahoo.com (S. C.K. Tay)

\section{To cite this article:}

Williams Walana, Eric Nana Kofi Aidoo, Ezekiel Kofi Vicar, Samuel Crowther Kofi Tay. Prevalence of Hookworm Infection: A Retrospective Study in Kumasi, Ghana. Science Journal of Public Health. Vol. 2, No. 3, 2014, pp. 196-199.

doi: $10.11648 /$ j.sjph.20140203.19

\begin{abstract}
Introduction- Epidemiological information such as trends of prevalence of hookworm infection is a prerequisite to developing and/or sustaining control strategies. Objective- This study specifically sought to establish the prevalence of hookworm infection among patients who reported at the Parasitology Laboratory of the Komfo Anokye Teaching Hospital (KATH) for intestinal parasitic investigation. Method- A retrospective study conducted covered available data from January 2001 to December 2011. Records of patients referred to the Parasitology Laboratory of the hospital were manually reviewed for hookworm infection. Data on age, sex and status of hookworm infection (either present or absent) were retrieved and analyzed using Microsoft excel 2007 statistical package. Results- A total of 47147 patients reported at the laboratory for intestinal parasitic investigations. Out of this number, 158 were hookworm positive, representing an overall prevalence of $0.3 \%(158 / 47147)$. Among the positive cases, the study revealed that the proportion of individuals in age groups $<1,1$ to 9,10 to 19,20 to 29 , and 30 to 39 years infected were $1.3 \%(2), 10.8 \%(17), 16.5 \%(26), 27.2 \%(43)$ and $23.4 \%(37)$ respectively. However, the proportion of patients in age groups 40 to 49,50 to 59 and $\geq 60$ years infected were $8.7 \%(14), 5.7 \%(9)$ and $7.0 \%(11)$ respectively. Among the infected patients $62.7 \%$ (99) were females while $37.3 \%$ (59) were males. The yearly prevalence rate dropped consistently from $0.8 \%$ in 2001 to $0.1 \%$ in 2005 . It however increased marginally in $2006(0.3 \%)$ and dropped to $0.0 \%$ in 2011 . There were indications of seasonal variation regarding the monthly prevalence rates of hookworm infection. Conclusion- The overall prevalence of hookworm was relatively low among the study population. However, the study suggests that hookworm infestation is generally high between April and August.
\end{abstract}

Keywords: Hookworm, Infection, Prevalence

\section{Introduction}

Hookworm is a parasitic nematode that lives in the small intestines of its hosts, mostly mammals such as dogs, cats, and human. Two species of hookworm commonly infect human: Ancylostoma duodenale and Necator americanus. They are voracious blood feeders of the nematode world $[1,2]$.

The most significant risk of hookworm infection is anaemia, secondary to loss of iron and protein in the gut [3]. It has been estimated that a single Ancylostoma duodenale ingests about $150 \mu \mathrm{L}$ of blood per day while Necator americanus sucks about $30 \mu \mathrm{L}$ [4]. However, the blood loss through this channel cannot be visualized with the naked eye.
In a situation where the worm burden is significantly high in an individual, infection is normally severe with iron deficiency anaemia, particularly in people with inadequate iron reserves or intake. In most developing countries for instance, anaemia in pregnancy has been associated with worm infestation, especially hookworm [5].

Worldwide, Necator americanus is the predominant aetiologic agent of human hookworm infection, whereas Ancylostoma duodenale is somehow restricted geographically [6, 7]. Most infected individuals are concentrated in sub-Saharan Africa and Eastern Asia/the Pacific Islands with each region having estimates of 198 million and 149 million infected individuals respectively $[8,9]$. 
Majority of these infected individuals live in poverty-stricken areas with poor environmental sanitation [10]. It is estimated that about 3,000 to 65000 deaths occur from hookworm related diseases annually worldwide [11, 12].

In Ghana, the Ministry of Health and the Ghana Health Service with the help of development partners put in place a Neglected Tropical Diseases Control Programme (NTDCP). The ultimate objective of the programme was to reduce Neglected Tropical Diseases (NTD) of which hookworm is no exception to a level that they will no longer be of public health significance by the year 2015 [13]. The target groups have generally been school children, young people and pregnant women. The current study focused on using available data at the Parasitology Laboratory of the Komfo Anokye Teaching Hospital to establish the prevalence of intestinal parasitic infection, particularly hookworm in the Kumasi metropolis.

\section{Materials and Methods}

\subsection{Study Design and Site}

This retrospective study was conducted at the Parasitology Laboratory of the Komfo Anokye Teaching Hospital (KATH). The hospital is located in Kumasi, the traditional and administrative capital of the Ashanti Region. Kumasi is about $170 \mathrm{~km}$ North West of Accra, the national capital. The Komfo Anokye Teaching Hospital hospital is accredited for postgraduate training in surgery, obstetrics and gynecology, otorhinolaryngology, ophthalmology, radiology, and other Allied Health programmes by the West African College of Surgeons. It currently has about 1000 beds capacity and serves as a referral hospital for the Ashanti, Brong-Ahafo and Western regions of Ghana.

\subsection{Data Extraction and Analysis}

All records of patients referred to the Parasitology Laboratory of the Komfo Anokye Teaching Hospital, from January 2001 to December 2011 were manually reviewed for hookworm infestation. Confirmation of the presence or the absence of intestinal parasite by the laboratory is based on microscopic examination of stool specimen using the direct wet mount technique as described by Cheesbrough [14]. Data on age, sex and status of hookworm infection were entered into and analysed using Microsoft excel 2007 statistical package.

\section{Results}

\subsection{Yearly Distribution of Hookworm Cases}

In total, 47147 patients were investigated for various intestinal parasitic agents during the period under review. Out of this number, $0.3 \%$ (158) were infected with hookworm. The highest prevalence was observed in 2001 $0.8 \%(45 / 5340)$ while no positive case of hookworm was recorded in 2011 (Table 1).
Table 1. Yearly distribution of positive cases of hookworm infection

\begin{tabular}{llll}
\hline Years & $\begin{array}{l}\text { Positive } \\
\text { hookworm cases }\end{array}$ & $\begin{array}{l}\text { Total number } \\
\text { of cases }\end{array}$ & Prevalence (\%) \\
\hline 2001 & 45 & 5340 & 0.8 \\
2002 & 35 & 5100 & 0.7 \\
2003 & 22 & 4840 & 0.5 \\
2004 & 11 & 3800 & 0.3 \\
2005 & 4 & 3780 & 0.1 \\
2006 & 12 & 4520 & 0.3 \\
2007 & 12 & 4600 & 0.3 \\
2008 & 9 & 3710 & 0.2 \\
2009 & 7 & 4107 & 0.2 \\
2010 & 1 & 3900 & 0.0 \\
2011 & 0 & 3450 & 0.0 \\
TOTAL & 158 & 47147 & 0.3 \\
\hline
\end{tabular}

\subsection{Cumulative Monthly Distribution of Hookworm Cases}

The cumulative monthly distribution of hookworm cases from 2001 to 2011 revealed that the number of positive cases was relatively higher in April 10.8\% (17/158) and August $10.1 \%(16 / 158)$ with peak infection seen in July $12.0 \%$ $(19 / 158)$. The rest of the months however showed varied distribution of hookworm positivity (Figure 1).

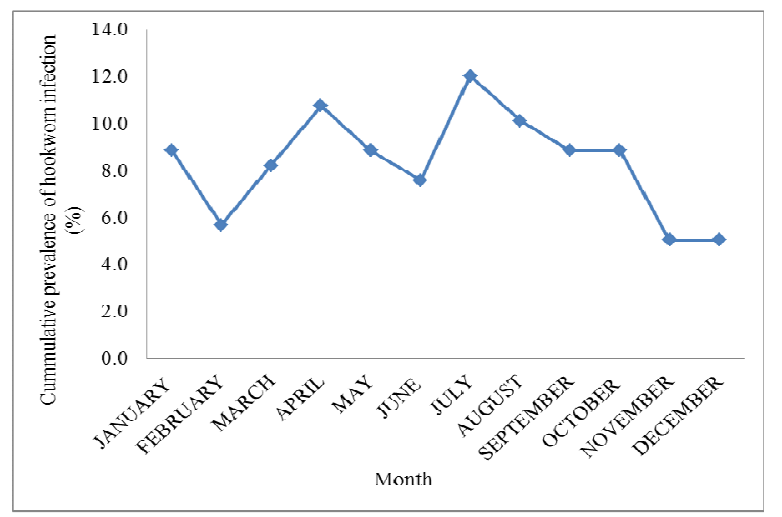

Figure 1. Cumulative monthly distribution of hookworm cases from 2001 to 2011.

\subsection{Age and Gender Distribution of Hookworm Infection}

Among the positive hookworm cases, infection was relatively higher in patients of age 10 to 39 years. Patient aged 40 years and above recorded prevalence not exceeding $8.9 \%$. However, the least infected group were patients below one year. More females were infected than male (Table 2).

Table 2. Age and gender distribution of hookworm infection

\begin{tabular}{llll}
\hline AGE(Years) & Male (\%) & Female (\%) & Total (\%) \\
\hline$<1$ & $1(50.0)$ & $1(50.0)$ & $2(1.3)$ \\
$1-9$ & $6(35.3)$ & $11(64.7)$ & $17(10.8)$ \\
$10-19$ & $12(46.2)$ & $14(53.8)$ & $26(16.5)$ \\
$20-29$ & $18(41.9)$ & $25(58.1)$ & $43(27.2)$ \\
$30-39$ & $10(27.0)$ & $27(73.0)$ & $37(23.4)$ \\
$40-49$ & $4(28.6)$ & $9(64.3)$ & $14(8.9)$ \\
$50-59$ & $5(55.6)$ & $4(44.4)$ & $9(5.7)$ \\
$\geq 60$ & $3(27.3)$ & $8(72.7)$ & $11(7.0)$ \\
TOTAL & $59(37.3)$ & $99(62.7)$ & $158(100.0)$ \\
\hline
\end{tabular}




\section{Discussion}

The current study focused on establishing the prevalence of hookworm among patients who visited the Parasitology Laboratory of the Komfo Anokye Teaching Hospital between 2001 and 2011. The period under review saw a total number of 47147 patients reporting to the Laboratory for intestinal parasitic investigations. Out of this number, 0.3\% (158) positive cases were recorded. The current year on year prevalence of hookworm infection recorded is relative low compared to studies conducted in Babile, eastern Ethiopia and Waikagul, which recorded $6.7 \%$ and $18.5 \%$ respectively [ 15 , 16]. There are reports that the disease is predominant among farming communities [11], a practice seemingly minimal in urban areas; hence the generally low prevalence observed.

The cumulative monthly distribution of hookworm cases from 2001 to 2011 revealed that the number of positive cases was high in April 10.8\%(17/158), August 10.1\%(16/158) and July $12.0 \%(19 / 158)$. April to August is the period in the year where farming activities are intensive, and individuals especially farmers are at higher risk of being infected with hookworm [17]. The ambient condition this period provides is condusive for the eggs of hookworm to hatch and develop into the infective form [18]. The results confirmed similar works which established the fact that seasonal variations affect the infectivity of hookworm [19-20].

Prevalence and intensity of hookworm infection have been associated with age and sex [21]. However, there appears to be considerable variation in the age-intensity profile of hookworm infestation in the current study. The study revealed that individuals less than 40 years are frequently infected with hookworm. This observation agrees with existing findings that prevalence of hookworm is high among younger people [22-24]. The high prevalence seen among individuals within the age bracket 10 to 39 years could be attributed to the fact that they are physically active and are more likely to be involved in activities such as farming and other manual works which predispose them to hookworm infection $[25,26]$. There are, however, reports that suggest that hookworm infection in the elderly could be relatively high $[27,28]$, as observed in the study.

Even though some studies have reported non-significant association between sex and hookworm infection [29, 30], the findings in this study showed otherwise as more females $62.7 \%$ (99) were infected than males $37.3 \%(56)$. However, this confirms work done by Akinbo et al., who reported high hookworm infection among females [19]. Cultural and social biases in behaviour and occupation have been established as risk factors influencing hookworm infection prevalence rates in males and females [31, 32]. The skewness in prevalence towards females results from the bias in the study since greater number of the stool samples investigated came from pregnant women who report to the laboratory for routine stool examination.

\section{Conclusion}

The study revealed that hookworm infestation among patients who reported at the Parasitology Laboratory of the Komfo Anokye Teaching Hospital from 2001 to 2011 is relatively low. However the prevalence of the disease was higher in females than males. Hookworm positivity was relatively high between April and August, and peaked in July.

\section{Acknowledgements}

We are grateful to the Polyclinic section of the Komfo Anokye Teaching Hospital, especially staff at the Parasitology Laboratory of the Polyclinic for assisting in this study.

\section{References}

[1] Ranjit N, Bin Zhan B, Hamilton B, Stenzel D, Lowther J, Pearson $\mathrm{M}$ et al. Proteolytic Degradation of Hemoglobin in the Intestine of the Human Hookworm. Necator americanus. J Infect Dis. 2009; 199 (6): 904-912.

[2] Pearson MS, Pickering DA, Tribolet L, Cooper L, Mulvenna J, Oliveira LM et al. Neutralizing Antibodies to the Hookworm Hemoglobinase Na-APR-1: Implications for a Multivalent Vaccine against Hookworm Infection and Schistosomiasis. J Infect Dis. 2010; 201(10): 1561-1569.

[3] Hotez PJ, Bethony JM, Diemert DJ, Pearson M, Loukas A. Developing vaccines to combat hookworm infection and intestinal schistosomiasis. In: Institute of Medicine (US) Forum on Microbial Threats. The Causes and Impacts of Neglected Tropical and Zoonotic Diseases: Opportunities for Integrated Intervention Strategies. Washington (DC): National Academies Press (US); 2011. A9.

[4] Midzi N, Mtapuri-Zinyowera S, Mapingure MP, Sangweme D, Chirehwa MT, Brouwer KC et al. Consequences of polyparasitism on anaemia among primary school children in Zimbabwe. Acta Tropica. 2010; 115(1-2): 103-111.

[5] Hotez PJ. Mass drug administration and integrated control for the world's high-prevalence neglected tropical diseases. Clin. Pharmacol. Ther. 2009; 85:659-664. doi: 10.1038/clpt.2009.16.

[6] Ngui R, Lim YAL, Chong Kin L, Sek Chuen C, Jaffar S. Association between Anaemia, Iron Deficiency Anaemia, Neglected Parasitic Infections and Socioeconomic Factors in Rural Children of West Malaysia. PLoS Negl Trop Dis. 2012; 6(3): e1550. Doi:10.1371/journal.pntd.0001550.

[7] Shaw JG, Friedman JF. Iron deficiency anemia: focus on infectious diseases in lesser developed countries. Anemia. 2011; 260380. doi: 10.1155/2011/260380.

[8] Hotez PJ, Brindley PJ, Bethony JM, King CH, Pearce EJ, Jacobson J. Helminth infections: the great neglected tropical diseases. J Clin invest. 2008;118:1311-1321.

[9] WHO Worldwide prevalence of anaemia 1993-2005. In: de Benoist B, McLean E, Egli I, Cogswell M, editors. WHO global database on anaemia. Geneva: 2008; World Health Organization. 
[10] Hotez PJ. Hookworm and poverty. Ann. N. Y. Acad. Sci. 2008; 1136: 38-44.

[11] Hotez PJ. The development impact of the neglected tropical diseases (NTDs). United Nations Department of Economic and Social Affairs Population Division. Expert Paper No. 2011/1. 2011; p1-40.

[12] Brooker S. Estimating the global distribution and disease burden of intestinal nematode infections: Adding up the numbers - A review. Int J Parasitol. 2010; 40(10): 1137-1144. doi: 10.1016/j.ijpara.2010.04.004

[13] MOH/GHS (2006), Two-year Strategic Plan for Integrated Neglected Tropical Diseases Control in Ghana, 2007-2008, p $1-41$.

[14] Cheesbrough M. District Laboratory Practice in Tropical Countries, Cambridge University Press, Cambridge, UK, 2005.

[15] Tadesse G. The prevalence of intestinal helminthic infections and associated risk factors among school children in Babile town, eastern Ethiopia. Ethiop.J.Health Dev.2005; 19(2): $140-147$.

[16] Yatich NJ, Yi J, Agbenyega T, Turpin A, Rayner JC, Stiles JK. Malaria and intestinal helminth co-infection among pregnant women in Ghana: prevalence and risk factors. Am J Trop Med Hyg. 2009; 80(6): 896-901.

[17] Febriani Y, Levallois P, Gingras S, Gosselin P, Majowicz SE, Fleury MD. The association between farming activities, precipitation, and the risk of acute gastrointestinal illness in rural municipalities of Quebec, Canada: a cross-sectional study. BMC Public Health 2010; 10(48). doi:10.1186/1471-2458-10-48.

[18] Bethony J, Brooker S, Albonico M, Geiger SM, Loukas A, Diemert $\mathrm{D}$ et al. Soil transmitted helminth infections; ascariasis, trichuriasis, and hookworm, Lancet 2006; 367(9521):1521-32.

[19] Akinbo FO, Okaka CE and Omoregie R. Seasonal variation of intestinal parasitic infections among HIV-Positive patients in Benin City, Nigeria. Ethiop. J. Health. Sci. 2011; 21(3): 191-194.

[20] Siwila J, Isaac P, Heidi Larsen E, Mbiko N, Annette O. Seasonal prevalence and incidence of Cryptosporidium spp. and Giardia duodenalis and associated diarrhoea in children attending pre-school in Kafue, Zambia. Trans R Soc Trop Med Hyg 2011; 105:102-108.

[21] Verhagen LM, Incani RN, Franco CR, Ugarte A, Cadenas Y, Ruiz SIC et al. High Malnutrition Rate in Venezuelan Yanomami Compared to Warao Amerindians and Creoles: Significant Associations WITH Intestinal Parasites and Anemia. PLoS ONE 2013; 8(10): e77581. doi:10.1371/journal.pone.0077581.

[22] Rayan P, Verghese S, McDonnel PA. Geographical locations and age affects the incidence of parasitic infestations in school children. Ind. J. Patho\& Microb. 2010; 53(3): 498-502.

[23] Mbae CK, Nokes DJ, Mulinge E, Nyambura J, Waruru A, Kariuki $\mathrm{S}$ et al. Intestinal parasitic infections in children presenting with diarrhoea in outpatient and inpatient settings in an informal settlement of Nairobi, Kenya. BMC Infectious Diseases 2013, 13:243. doi:10.1186/1471-2334-13-243.

[24] Osazuwa F, Ayo OM, Imade P. A significant association between intestinal helminth infection and anaemia burden in children in rural communities of Edo state, Nigeria. North Am J Med Sci. 2011; 3: 30-34. doi: 10.4297/najms.2011.330.

[25] Brooker S, Jardim-Botelho A, Quinnell RJ, Geiger SM, Caldas RS, et al. (2008) Age-related changes in hookworm infection, anaemia and iron deficiency in an area of high Necator americanus hookworm transmission in south-eastern Brazil. Trans R Soc Trop Med Hyg. 2008; 101: 146-154. doi: 10.1016/j.trstmh.2006.05.012.

[26] Abu-Madi MA, Behnke JM, Doiphode SH. Changing trends in intestinal parasitic infections among long-term-residents and settled immigrants in Qatar. Parasites \& Vectors 2010; 3:98. doi:10.1186/1756-3305-3-98.

[27] Rayan P, Verghese S, McDonnel PA. Geographical locations and age affects the incidence of parasitic infestations in school children. Ind. J. Patho\& Microb. 2010; 53(3): 498-502.

[28] Lim YA, Romano N, Colin N, Chow SC, Smith HV Intestinal parasitic infections amongst Orang Asli (indigenous) in Malaysia: has socioeconomic development alleviated the problem? Trop Biomed. 2009; 26(2):110-122.

[29] Phongluxa K, Xayaseng V, Vonghachack Y, Akkhavong K, van Eeuwijk P, Odermatt P. Helminth infection in southern Laos: high prevalence and low awareness. Parasites \& Vectors 2013, 6:328. doi:10.1186/1756-3305-6-328.

[30] Nasr NA, Al-Mekhlafi HM, Ahmed A, Roslan MA, Bulgiba A. Towards an effective control programme of soil-transmitted helminth infections among Orang Asli in rural Malaysia. Part 1: prevalence and associated key factors. Parasit Vectors. 2013; 6(27). doi: 10.1186/1756-3305-6-27.

[31] Okwa OO. Tropical Parasitic Diseases and Women. Annals of African Medicine. 2007; 6(4): 157 - 163.

[32] Walker M, Hall A, Basáñez M-G. Individual Predisposition, Household Clustering and Risk Factors for Human Infection with Ascaris lumbricoides: New Epidemiological Insights. PLoS Negl Trop Dis. 2011; 5(4): e1047. doi:10.1371/journal.pntd.0001047. 